\title{
DOCENCIA E INVESTIGACIÓN EN LA CONSTRUCCIÓN DEL CONOCIMIENTO CIENTÍFICO: REFLEXIONES PARA LA CIENCIA JURÍDICA ${ }^{1}$
}

Teaching and Research in the Construction of Scientific Knowledge: Exploring Legal Science ${ }^{1}$

\section{$\underline{\text { Abraham Zamir Bechara Llanos }}^{2}$}

Fecha de Recepción: Mayo 5 de 2014

Fecha de Aceptación: Mayo 12 de 2014

SUMARIO: 1. Introducción; 2. Investigación, conocimiento y ciencia; 3. Docencia e investigación en la construcción del conocimiento científico; 4. La ciencia hoy, la ciencia en el siglo XXI; 5. Conclusiones;

6. Referencias bibliográficas.

\footnotetext{
${ }^{1}$ Este artículo de investigación es resultado del proyecto titulado: La investigación jurídica y la ciencia en el siglo XXI. Adscrito al grupo Teoría Jurídica y Derechos Fundamentales "phrónesis" de la Facultad de Derecho de La Universidad Libre Seccional Cartagena. Línea de investigación: Teoría de la ciencia jurídica. La financiación de este artículo ha sido a cargo de la Facultad de Derecho y Ciencias Políticas de la Universidad de Cartagena.

${ }^{2}$ Abogado y Especialista (Ex Becario Unilibre) en Derecho Constitucional de la Universidad Libre Sede Cartagena. Candidato a Magíster en Derecho Modalidad Investigación Universidad del Norte. Miembro del Grupo de Investigación Teoría Jurídica "phrónesis" de la Universidad de Cartagena. E-mail: abrahambechara@hotmail.com
} 


\section{COMO SE CITA ESTE ARTÍCULO (APA 6)}

Bechara Llanos, A. Z. (2014) Docencia e investigación en la construcción del conocimiento científico: reflexiones para la Ciencia Jurídica. (Y. Carrillo De la rosa, Ed.) Revista Jurídica Mario Alario D'Filippo, VI (12), pág. 98-107

\section{RESUMEN}

Este artículo se fundamenta en la necesidad de enfocar la educación hacia la investigación teórico-práctica, aplicada al cambio de las realidades sociales. Parte de la llamada construcción teórica de la ciencia en el marco del siglo de las tecnologías, que persigue la conformación de espacios lógicos de interacción académica, apoyados en la epistemología de la ciencia, en la teoría sistémica del profesor Luhmann, en teóricos de la ciencia moderna (Michel Foucault), y en el enfoque comunicativo de Habermas. Además, utiliza importantes referentes teóricos, como los estudios del desarrollo humano aplicado a la noción de conocimiento y de ciencia social, de Sen, así como la posición de Carrillo de la Rosa en el replanteamiento del paradigma y objeto de estudio en las ciencias sociales.

\section{PALABRAS CLAVE}

Docencia, ciencia, siglo XXI, investigación, epistemología.

\section{ABSTRACT}

This article is based on the need to focus education towards the theoretical and practical research, applied to changing social realities. Part of the so-called theoretical construction of science under the century technology, which seeks the creation of logical spaces of academic interaction, supported by the epistemology of science, systems theory of Professor Luhmann, in theoretical science modern (Michel Foucault), and the communicative approach of Habermas. It also uses important theoretical references, such as studies of human development applied to the notion of knowledge and social science, Sen, and the position of Carrillo de la Rosa in rethinking the paradigm and object of study in the social sciences.

\section{KEYWORDS}

Teaching, Science, XXI century, research, epistemology. 


\section{INTRODUCCIÓN}

La tesis que defenderé en el presente ensayo, es aquella que afirma, que el docente del siglo XXI debe ser investigador. Para ello, reflexionaremos acerca de la pregunta, ¿̇la actividad de docencia debe ser complementaria en la investigación o es esta una acción implícita en el docente contemporáneo? Además articulada como sub-pregunta de investigación se erige la siguiente, ¿̇y cuál es el papel de la ciencia en el siglo XXI articulado con el rol del docente de nuestros días?

En aras de resolver estos interrogantes, se estructura la hipótesis, de considerar al docente moderno como una persona dotada, no solo de habilidades teórico-conceptuales para el desarrollo y despliegue de sus actividades propias de su asignatura, materia, o especialidad profesional. Sino de facultades y competencias propias en la investigación como componente científico de sus capacidades profesionales. Que le proporcionaría al docente mejores herramientas, ligadas estrechamente con la potencialización de sus habilidades, ese docente debe estar articulado por los nuevos paradigmas de la ciencia, o su concepción moderna, hasta llegar a hacer posible construir su propia aproximación al fenómeno científico, ya que la construcción de tal estadio, solo es posible si se articula con el rol de un docente más dinámico, más activo, prospectivo con su entorno, y ese imaginario colectivo, es posible si ese docente se apoya en la investigación como fuente creadora de conocimiento. Su análisis y debates, el de este ensayo estarán apoyados, desde una construcción analítica de tipo reflexivo sobre los avatares del rol docente como investigador como plus de su desarrollo académico-profesional.

Un docente investigador, miraría todos los universos posibles, no solo desde su experiencia laboral o profesional, sino con gran sentido crítico, que le permitiría generar una visión holística de todos los elementos que interactúan en el proceso de la educación, y el rol de la docencia en escenarios de mayor crédito. Al respecto del proceso de investigación en educación superior Ramírez Llerena (2001) indica: "la investigación es un proceso mediante el cual, con la aplicación del método científico, se requiere obtener información relevante y fidedigna para entender, verificar, corregir o aplicar el conocimiento". (p. 6). Esto, nos pone de presente que los procesos, que se realizan en la investigación permiten optimizar los rangos de búsqueda y verificación del conocimiento, que se va a trasmitir a los estudiantes de una forma más estructurada y mejor orientada, tendiente a producir excelentes resultados en la asignatura que se está desarrollando. Y construyendo siempre los contenidos con importante sentido crítico y reflexivo.

\section{INVESTIGACIÓN, CONOCIMIENTOY CIENCIA}

Hoy hablar de investigación, es hablar desde la misma noción y entendido del conocimiento, ya que el proceso de producción investigativo, tiene una fuerte orientación a la construcción de conocimiento, e inclusive perfilándose como su deber ser garantizador y dinamizador de la ciencia en su sentido amplio y general, por eso, es vital que el rol de la docencia en el siglo XXI apoyado desde una construcción de la ciencia actual, permite consolidar espacios comunes o vasos comunicantes de interacción y efecto entre las posibles fuentes del saber científico, y su aplicabilidad a los saberes disciplinares y curriculares. 
En este contexto, otros estudios en las ciencias sociales concretamente, como las del sociólogo profesor Niklas Luhmann, han permitido establecer criterios de construcción en el campo de la docencia con innovación y rigor científico, los cuales orientan la visión del educador como un articulador de los miles de sistemas que conforman el mundo o el universo del conocimiento. Según este sociólogo, el conocimiento y su búsqueda están ligados a la decantación de un gran sistema social, lo que él denomina la teoría sistémica. Este gran sistema se nutre, de lo político, lo social, lo religioso, lo cultural y lo económico. Pero la mejor búsqueda de este sistema es a través de la investigación de los conocimientos, que permitan desarrollar la especialidad que desempeñe cada docente en los campos específicos. Ese modelo sistémico de la gestación del conocimiento, se apoya además de una perspectiva constructivista, ya que en apoyo de estos postulados el docente, al interactuar con su saber disciplinar, siempre debe partir de postulados empíricos generales, que le permitan posteriormente materializar la experiencia de sus sentidos en una razón práctica, ya no existencial sino objetivo-material.

La sociedad como sistema autopoietico, va a permitir la construcción de un conocimiento complejo, pero dicho conocimiento debe estar regulado por la condición de que cumpla una posición dentro del sistema. Es importante establecer la relación derecho y autopoiesis con relación al individuo.

Michel Foucault (post-estructuralismo), Jürgen Habermas (teoría crítica) y Niklas Luhmann (teoría de la autopoiesis). Dichas teorías tienen en común el hecho de que reemplazan al individuo autónomo por procesos comunicativos y no por entidades supra-individuales. Difieren, por el contrario, en su identificación de la nueva unidad cognitiva. En la concepción de la teoría crítica de Habermas, las correspondientes teorías de la verdad se ven desbancadas por las teorías del consenso y la «intersubjetividad» toma el lugar del sujeto epistémico. Foucault y Luhmann son todavía más radicales en su desencantamiento con el sujeto individual. Para Foucault, el individuo no es sino una construcción efímera de la constelación, históricamente contingente, poder/discurso, la cual dicta el episteme de una época histórica. Luhmann separa totalmente los procesos psíquicos de los sociales y percibe al individuo en la sociedad como un artefacto semántico, como un producto de la auto-observación de la autopoiesis social. Los nuevos sujetos epistémicos son los sistemas sociales autopoieticos". (Teubner, 1989, pp. 16-17)

Es ese rechazo del ser supra-individual o del macro-individuo, lo que desarrolla aplicado a nuestra tesis, la concepción de un docente investigador gestor del conocimiento, ya que este rompe paradigmas clásicos de la pedagogía al considerar que el docente era autosuficiente en la gestación de su saber, ya este paradigma se va a replantear con la nueva idea de ciencia, al destacar que el docente se debe al constante interactuar, con sus críticos que en este caso son sus estudiantes, pues esa crítica, es la que va a permitir la retroalimentación, de nuevas ideas, posturas, teorías, y por qué no, de nuevo conocimiento.

En este entendido, los sistemas sociales autopoieticos, buscan la construcción del individuo a partir de su posición en la consolidación social del sistema, esto plantea que al igual que la complejidad que el sistema presenta por tener un sinnúmero de condiciones y de realidades, al igual, el 
individuo como producto de la esfera y el universo social, comprende gran cantidad de complejidades.

Cada una de ellas va a permitir que el individuo encuentre su espacio en la complejidad social construida a través de las paradojas de la autoreferencia:

Las paradojas de la auto-referencia parecen ser el principal obstáculo para el desarrollo de una verdadera epistemología social. Habermas y Foucault han realizado importantes contribuciones, pero las consecuencias radicales de sus ideas parecen estar bloqueadas por las estructuras auto-referenciales (circularidad, tautología, regresión infinita, paradoja) a lo largo de sus versiones de la teoría del discurso. ¿Cómo puede justificarse el discurso racional sino por el propio discurso racional (Habermas)? ¿Cómo pueden ser transformadas esas formaciones discursivas que gobiernan el epistème de toda una época histórica sino por las propias formaciones discursivas (Foucault)? Ambos autores son plenamente conscientes de que estas cuestiones llevan necesariamente a la paradoja, y sin embargo su solución es la de evitar la paradoja a cualquier precio. Evidentemente las paradojas de la auto-referencia no pueden evitarse: simplemente reaparecen al final de cualquier vía de escape. Cuando Habermas encuentra la fundamentación trascendental de la comunicación en la distinción entre situación ideal del discurso y las situaciones reales del discurso, ¿es esta distinción a su vez, empírica o trascendental? De forma alternativa, cuando reintroduce el sujeto en el discurso, las paradojas clásicas del sujeto autorreflejado están obligadas a reaparecer. Cuando Foucault establece la fundamentación del discurso en las constelaciones de poder ubicuas, lo hace a cambio de las paradojas autoreferenciales del poder. (Teubner, 1989, pp. 24-25)

Es así, que la relación que presenta la manera en que las paradojas operan en el sistema autopoietico, que el mismo se encarga de encontrar en sus propios elementos las condiciones para la realización de sus fines. La construcción autopoietica, al considerar sistémicamente una producción del sujeto condicionado a lo social, evita que existan choques entre sus propios elementos y los elementos que el sistema proporciona, ya que si bien se presenta así mismo, como una complejidad de elementos, los mismos se autorregulación y referencia en el sentido que cada uno cumpla un papel en su interior complejidad, así va a permitir, que la sincronía y adecuación de sus elementos y componentes esté asegurada y con estos se evitan las mismas paradojas que el mismo sistema autorrefencia en su universo de condicionantes. Es decir, la paradoja en el desarrollo sistémico del conocimiento siempre va a existir, pero esta paradoja es importante para dotar de equilibrio y proporcionalidad a todo el gran sistema científico, pues la paradoja, se construye por analogía en la docencia, a la falibilidad, y refutabilidad de los argumentos que se construyen con la posición teórico-científica, es más las relaciones, entre conocimiento, sistema, ciencia e investigación, son las mismas condicionantes que se relacionan, en los sistemas autopoieticos, que buscan la realización del ser como individuo social enmarcado en una gran campo de acción llamado sistema.

Estas condicionantes, permiten hacer una construcción social de la realidad, ya que todos los procesos que se construyan al interior del sistema, expresan condicionantes externas, de su realidad, como son las circunstancias sociales. Vital en esta postura, es establecer que si bien existen condicionantes internas y externas, de la realidad, ambos conceptos estrechan sus líneas y 
contribuyen a una aproximación conjunta del sistema social, aportando ambas construcciones.

Ya que la construcción de lo individual, nunca podrá ser abordada únicamente desde su marco de acción subjetivo, sino que responde a parámetros de concreción intra y extra subjetivos.

En esta versión radicalizada de la «construcción social de la realidad» no hay lugar para la acción o el pensamiento individual. La autopoiesis social se basa exclusivamente en la comunicación - definida como la síntesis de participación, información y comprensiónque recursivamente reproduce la comunicación. La construcción social de la realidad está fuertemente separada de la construcción psíquica de la realidad. En este punto radica la importante diferencia con Habermas, quien en el ambiguo concepto de intersubjetividad funde comunicación y conciencia; también con Foucault, para quien el sujeto no es sino un constructo históricamente contingente de las constelaciones oscilantes discurso / poder. Para la teoría de la autopoiesis, los procesos psíquicos forman su propia red reproductiva cerrada -autopoiesis psíquica-. Esta solo es accesible a ellos mismos y se muestra totalmente inaccesible a la comunicación. (Teubner, 1989, p. 28)

\section{DOCENCIA E INVESTIGACIÓN EN LA CONSTRUCCIÓN DEL CONOCIMIENTO CIENTÍFICO}

En este orden ideas, pensemos en un docente que llegue a sus estudiantes con sus propios escritos, como artículos, ponencias, relatorías, libros, entre otras maneras de difundir sus conocimientos, y esto le permita al docente retroalimentarse continuamente de las discusiones, debates y dudas a la reflexión de la interacción de este con sus alumnos. Podemos visionar, un docente más en el plano de lo académico-investigativo que estrechamente se vincula al campo de la construcción de un conocimiento científico.

Este docente del siglo XXI, debe estar siempre dispuesto al libre pensamiento y desarrollo de las ideas, ya que la verdad absoluta nunca será la opción, debido a que la única verdad será la que se construya en clase con la intervención de los estudiantes, inclusive estando esta verdad relativizada, hasta que otra tesis, hipótesis o teoría no cambia la perspectiva conceptual que se venía manejando. Este docente esta, más de la mano de una democratización de la educación y del conocimiento, pues al apoyarse en herramientas, de la experiencia y la razón, conformaría un binomio perfecto, entre el conocimiento basado en lo experimental y el conocimiento basado en un método puro del campo teórico.

Invitamos así, a la materialización de una nueva era de la práctica docente, orientada en construir un conocimiento libre, alejado de dogmas, secularismos ortodoxos, y enfocado más bien por la constante experimental de doble vía entre los estudiantes pro-activos y el docente como guía de ellos. He aquí, un propósito en sí mismo, un plus adicional que el docente de nuestros tiempos debe descubrir no solo en una formación de posgrado o en una educación continuada, más bien ese docente en tiempos de posmodernidad se forma intrínsecamente, en sus niveles primarios, como lo es el pregrado, desenvolviéndose en los múltiples escenarios que trae el desarrollo de los estudios en un marco de la interacción constante con otras latitudes y saberes multidisciplinares, nos referimos entonces a la construcción del docente no solo como aquel individuo que fue excelente en sus estudios, como muestra de una garantía de un aprendizaje tradicional, sino más 
bien, formado al interior de los escenarios globales y locales-multisectoriales como lo son los semilleros de investigación, aquí la semilla es importante, pues los perfiles que se construyan más adelante tendrán un fuerte anclaje en la construcción no solo de nuevas hipótesis y problemas para responder a las inquietudes de los saberes, sino gran gestación y creación del conocimiento, más aun, en la aplicación local de los focos nodales de pensamiento y discusión.

Por qué hacemos tanto hincapié en la construcción del rol docente, estamos frente a un modelo pedagógico de corriente tradicional, o más bien desarrollamos un modelo de enseñanza basado en la construcción crítica de las ideas. La segunda hipótesis podría estar más cerca a lo que aquí nos proponemos, y es precisamente como podemos desarrollar escenarios de pensamiento basados en un modelo de aprendizaje crítico, y reflexivo sobre todo. Nosotros somos de la idea central, que esto es posible con el valor agregado que pone de presente la investigación, ya que la investigación siempre debe partir de una técnica del pensamiento problémico, o lo que se denomina como "tópica".

La tópica que está estrechamente ligada a la investigación, le va a permitir al actor o a quien la ponga en práctica construir escenarios bajo la guía y lógica problémico, para orientar así su desarrollo a la búsqueda de respuestas o soluciones concretas a los entendidos empíricos o dialógicos, dentro de una estructura racional. Pues será esa técnica del pensamiento problémico, lo que nos permitirá destruir las aporías del conocimiento, o problemas acuciantes que necesitan respuesta, pues aquí la certidumbre va a imponer su límite, amparado en una razonamiento deconstructivo para la generación de nuevas ideas, mejores enfoques, y múltiples respuestas, para afrontar ya no solo una respuesta correcta aun solo problema o interrogante, sino una baraja de soluciones que permiten construir la integralidad en la búsqueda del conocimiento basado en un aprendizaje construido en el rol de la docencia investigativa.

\section{LA CIENCIA HOY, LA CIENCIA EN EL SIGLO XXI}

Ahora bien, como segundo componente de nuestro ensayo reflexionaremos y debatiremos entorno al concepto de ciencia hoy o ciencia en siglo XXI. El concepto de ciencia hoy, está ligado a múltiples factores. Uno de ellos es el propio ser o individuo como una intersubjetividad de elementos que construyen una realidad, realidad que debe ser vista desde sus componentes sociales, y de como aquellos aportes de lo humano construyen espacios para imaginarios colectivos que apunten siempre a la búsqueda del deber ser en una racionalidad o racionalización de los procesos sociales. Habermas propone una visión de la ciencia como realidad técnica e instrumental para el desarrollo de la sociedad:

La progresiva racionalización de la sociedad depende de la institucionalización del progreso científico y técnico. En la medida en que la ciencia y la técnica penetran en los ámbitos institucionales de la sociedad, transformando de este modo a las instituciones mismas, empiezan a desmoronarse las viejas legitimaciones. La secularización y el desencantamiento de las cosmovisiones, con la pérdida que de ellos implica de su capacidad de orientar la acción, y de la tradición cultural en su conjunto, son la otra cara de la creciente racionalización de la acción social. (Habermas, 1986, pp. 53-54) 
Es así, como se vislumbra que la construcción de la ciencia hoy, debe estar fuertemente ligada, a la idea de lo racional, y con ello la propia búsqueda de la cientificidad no solo en el discurso jurídico sino en todos los ámbitos y escenarios que desplieguen la actividad humana, ya que con esto el hombre en aras de la racionalización de sus procesos debe caminar de la mano de la ciencia y sus herramientas que le permitan construir sus campos de conocimiento.

Por otro lado, hay autores que consideran que estamos perdiendo la realización lógica de nuestros comportamientos y acciones por un consecuencialismo de lo cotidiano que se construye a medida que vamos afrontando situaciones concretas:

En los últimos años la imagen de los adolescentes y adultos como «animales racionales» ha cambiado profundamente en la psicología del pensamiento. De seres dotados de una lógica, formal o natural, innata o construida, hemos pasado a ser personas dominadas por tendencias intuitivas poco "lógicas», de dudosa racionalidad y plagadas de sesgos en nuestro razonamiento. Se ha ido imponiendo cada vez más la idea de que las personas nos regimos más por criterios de conveniencia pragmática que de coherencia lógica. (Pozo, Sanz, Gómez \& Limón, 1991, p. 85)

Lo que nos llevaría a pensar, que la construcción racional de las acciones en el hombre, podría depender de como el mismo ser entiende la idea de realización de su campo de interés, y de cómo se va a desempeñar en la sociedad a partir de su rol.

En este orden de ideas, la ciencia en la actualidad se construye desde un punto de vista económico, por una ideología capitalista, donde la producción en masa del conocimiento que más tarde pueda traducirse en tecnología, marcando la pauta en los países desarrollados, y a aquellos que no lo están simplemente contribuyen al proceso de industrialización con sus materias primas y productos esenciales para la fabricación y elaboración de otros procesos. Varsavsky ilustra este momento:

La ciencia actual, en resumen, está adaptada a las necesidades de un sistema social cuyo factor dinámico es la producción industrial masificada, diversificada, de rápida obsolescencia; cuyo principal problema es vender -crear consumidores, ampliar mercados, crear nuevas necesidades o como quiera decirse- y cuya institución típica es el gran consorcio, modelo de organización y filosofía para las fuerzas armadas, el gobierno y las universidades. Es lógico que este sistema estimule la especialización, la productividad, la competitividad individual, la invención ingeniosa, el uso de aparatos, y adopte criterios cuantitativos, de rentabilidad de inversiones para evaluar de todo tipo de actividad. Esto se refleja, hemos visto, en la ciencia actual de todo el mundo: en los países desarrollados por adaptación, y en los demás por seguidismo, por colonialismo científico. (Varsavsky, 1969. p. 17)

La ciencia hoy, debe tener un doble compromiso, un compromiso social y un compromiso moral, el primero debe buscar que la ciencia construya realidades que le permitan a todos disfrutar de sus avances y conocimientos en beneficio de las masas y de los colectivos, que no despliegue su capacidad a construir riquezas individuales o particulares, ya que si se pude construir un bienestar que aporte al desarrollo de las naciones y los menos favorecidos. 
La ciencia hoy es desarrollo y progreso, Sen refleja la posición de los menos favorecidos en desventaja, con los procesos industriales y tecnológicos que permite desarrollar la ciencia:

El desarrollo requiere de la eliminación de importantes fuentes de la ausencia de libertad como son: pobreza y tiranía, oportunidades económicas escasas y privaciones sociales sistémicas, falta de servicios públicos, intolerancia y sobre actuación de Estados represivos. A pesar del incremento sin precedentes de la opulencia global, el mundo contemporáneo niega libertades elementales a enormes cantidades de personas, si no es que a la mayoría. Unas veces la falta de libertades reales se relaciona directamente con la pobreza económica, que priva a la gente de la libertad de satisfacer el hambre, alcanzar una nutrición adecuada, obtener remedios para enfermedades curables, contar con techo y abrigo, agua limpia e instalaciones sanitarias. (Sen, 2000. p. 14)

Uno de los principales retos de la ciencia en la actualidad, es que ella genere un cambio social, y en esta búsqueda del cambio social, la misma ciencia se enfrenta a problemas estructurales del "mismo sistema", como Varsavsky lo llama estabilidad del sistema:

La sociedad actual tiene una cantidad de fuerzas disolutivas en acción, y una cantidad de mecanismos de defensa contra ellas. Es necesario plantear esta situación en toda su generalidad, y a un nivel mucho más concreto que los slogans sobre las condiciones del capitalismo, pensado en la acción. Tiene problemas técnicos, muchos de ellos producidos por el crecimiento demográfico y económico, como la contaminación, el suministro de agua, la ineficiencia de la burocracia, la decadencia de la educación formal, el desorden en la organización del trabajo -desde los problemas de tráfico hasta las migraciones incontroladas-, etcétera. (Varsavsky, p. 23)

Como ya lo hemos mencionado, las características principales de los postulados a los que responde la ciencia hoy, no fueron los mismos siempre, ya que la ciencia en sus orígenes se identificó por el descubrimiento y acercamiento al conocimiento y la búsqueda del saber. Como lo identifica Carrillo (2008):

La distinción o separación tradicional que se hace entre investigación o ciencia pura, desinteresada y objetiva, cuyo conocimiento surge de la actitud o deseo del hombre de explicar y comprender su realidad, y la ciencia aplicada está siendo borrado como consecuencia de la cientifización de la técnica y del mercado. Este hecho ha contribuido a borrar los límites que existían entre la ciencia como actividad que pretendía explicar teóricamente la realidad, como un fin en sí misma y sus aplicaciones en una tecnología específica. La revolución industrial expresa esencialmente esa disolución entre la ciencia como una actividad pura, teórica y desinteresada y la de la ciencia como un discurso del poder. Hoy día está claro que es el marco de las aplicaciones de la ciencia (industria alimenticia, bélica, farmacéutica, etc.) es la que decide y orienta la investigación pura. (p. 19) 


\section{CONCLUSIONES}

Como gran conclusión del presente estudio, evidenciamos que la investigación en tiempos de modernidad entra en una contante tensión frente a los avatares de la ciencia en el siglo XXI, principalmente por los procesos de "instrumentalización" e "industrialización del conocimiento". La docencia debe afrontar este reto especialmente desde proceso de ciencia pura o de construcción de nuevo conocimiento, esto es posible si solo el rol del maestro gira entorno a la construcción crítica de tales teorizaciones directamente desde su insumo principal que son las aulas de clases.

Específicamente para el derecho, la investigación en la ciencia jurídica del nuevo siglo de regirse por esta acción proactiva de quien enseña el derecho, no solo desde su experticia o saber disciplinar, sino desde el saber investigativo que construye el nuevo derecho, aplicando no solo un método científico propio de las ciencias sociales, sino un método autónomo del saber jurídico en particular.

\section{REFERENCIAS BIBLIOGRÁFICAS}

CARRILLO, Y. (2008) “Problemas y paradigmas de las ciencias sociales y la ciencia jurídica”. Universidad Libre Cartagena, Centro de Investigaciones. Colombia.

HABERMAS, J. (1986) “Ciencia y técnica como ideología”. Traducción por Manuel Jiménez Redondo. Tecnos. Madrid.

POZO, J., SANZ, A., GÓMEZ, M.A. \& LIMÓN, M. (1991) “Historia y epistemología de las ciencias”. En: Revista Enseñanza de las ciencias. Universidad Autónoma de Madrid. V. 9.

RAMíREZ, E. (2001) "La investigación socio-jurídica, aproximaciones críticas". Ediciones Doctrina y Ley. Bogotá, Colombia.

SEN, A. (2000) "El desarrollo como libertad". Traducción de Luz María Mohar. En: Revista Gaceta Ecológica. $\mathrm{N}^{\circ} 55$.

TEUBNER, G. (1989) “El derecho como sujeto epistémico: hacia una epistemología constructivista del derecho". Doxa, Cuadernos de Filosofía del derecho. $\mathrm{N}^{\circ} 25$.

VARSAVSKY, O. (1969) “Ciencia, política y cientificismo". Centro Editor de América Latina, Buenos Aires. Argentina. 